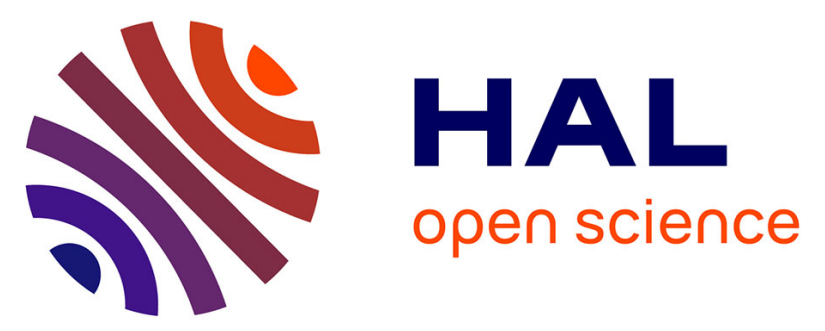

\title{
Assessment of Quadrilateral Fitting of the Water Column Contribution in Lidar Waveforms on Bathymetry Estimates
}

Lydia Abady, Jean-Stéphane Bailly, Nicolas Baghdadi, Yves Pastol, Hani Abdallah

\section{To cite this version:}

Lydia Abady, Jean-Stéphane Bailly, Nicolas Baghdadi, Yves Pastol, Hani Abdallah. Assessment of Quadrilateral Fitting of the Water Column Contribution in Lidar Waveforms on Bathymetry Estimates. IEEE Geoscience and Remote Sensing Letters, 2014, 11 (4), pp.813 - 817. 10.1109/LGRS.2013.2279271 . hal-01521989

\section{HAL Id: hal-01521989 \\ https://hal.science/hal-01521989}

Submitted on 12 May 2017

HAL is a multi-disciplinary open access archive for the deposit and dissemination of scientific research documents, whether they are published or not. The documents may come from teaching and research institutions in France or abroad, or from public or private research centers.
L'archive ouverte pluridisciplinaire HAL, est destinée au dépôt et à la diffusion de documents scientifiques de niveau recherche, publiés ou non, émanant des établissements d'enseignement et de recherche français ou étrangers, des laboratoires publics ou privés. 


\title{
Assessment of Quadrilateral Fitting of the Water Column Contribution in Lidar Waveforms on Bathymetry Estimates
}

\author{
Lydia Abady, Jean-Stéphane Bailly, Nicolas Baghdadi, Yves Pastol, and Hani Abdallah
}

\begin{abstract}
A new approach based on a mixture of Gaussian and quadrilateral functions was developed to process bathymetric lidar waveforms. The approach was tested on two simulated data sets obtained from the existing Water-LIDAR (Wa-LID) waveform simulator. The first simulated data set corresponds to a sensor configuration modeled after a possible future satellite bathymetric lidar sensor that was previously studied. The second simulated data set corresponds to a lidar airborne configuration modeled using the HawkEye airborne lidar parameters. In the proposed approach, the lidar waveform is fitted into a combination of three functions, two Gaussians for both the water surface and water bottom contributions and a quadrilateral function to fit the water column contribution. The results show more accurate bathymetry estimates compared with the use of a triangular function to fit the column contribution or a simple peak detection method. For the satellite configuration, the bias is improved by 16.8 and $0.8 \mathrm{~cm}$ compared with the peak detection method and the use of a triangular function, respectively. For the airborne configuration, the bias is improved by 10.0 and $2.4 \mathrm{~cm}$ compared with the peak detection method and the use of a triangular function, respectively. The proposed waveform fitting using the quadrilateral function underestimates the bathymetry by -5.0 and $-6.1 \mathrm{~cm}$ for the simulated satellite and airborne data sets, respectively. The standard deviations of the bathymetry estimates are 6.0 and $8.2 \mathrm{~cm}$, respectively. The obtained biases are inherent to overlaps between functions fitting the water surface, column, and bottom contributions.
\end{abstract}

Index Terms - Lidar bathymetry, quadrilateral, recursive fitting, water column contribution, waveform processing.

\section{INTRODUCTION}

$\mathbf{L}$ IDAR is an active remote sensing system that can be used to estimate altimetry and bathymetry. However, to date, there has not been any lidar satellite mission usable to bathymetry due to low laser power or unsuitable wavelengths to penetrate water [5]. Nevertheless, airborne lidar bathymetry (ALB) is recognized as an efficient tool that is able to swiftly collect information to evaluate the effects of natural disasters (flooding and hurricanes) and is also beneficial in hydrography and hydrological applications (see [2], [5], and [6]).

Manuscript received March 5, 2013; revised May 29, 2013, July 18, 2013, and July 24, 2013; accepted August 10, 2013. Date of publication November 7, 2013; date of current version December 2, 2013.

L. Abady, N. Baghdadi, and H. Abdallah are with the Irstea, UMR Territoire, Environnement, Télédetection et Information Spatiale, 34093 Montpellier Cedex 5, France.

J.-S. Bailly is with the AgroParisTech, UMR Territoire, Environnement, Télédetection et Information Spatiale, UMR Laboratoire d'Intercations Sol-Agrosystèmes-Hydrosystèmes, 34093 Montpellier Cedex 5, France.

Y. Pastol is with the Service Hydrographique et Océanographique de la Marine, 29228 Brest Cedex 2, France.

Digital Object Identifier 10.1109/LGRS.2013.2279271
The water depth is usually computed by subtracting the bottom return time from the surface return time of the laser beam and then multiplying this time difference by half the speed of light in water [7]. Typically, a part of the laser energy is lost due to Fresnel reflectance at the water surface, scattering, and absorption in the water, which will limit the strength of the bottom return and, hence, limit the maximum detectable depth (see [7] and [8]). However, the most limiting factor of lidar bathymetry is the optical water clarity depending on scattering and absorption within water [7], which affects the water column contribution in the waveform, registering the backscattered energy along time.

A typical bathymetric lidar waveform contains a surface contribution, a column backscattered contribution, a bottom contribution, and background noise contributions. To retrieve a more accurate bathymetry from bathymetric waveforms, several postprocessing approaches can be used. Among these approaches are fitting process and mathematical approximations, heuristic methods (such as the simple peak detection method), statistical approaches, or deconvolution methods [9]. However, despite being efficient, fitting approaches do not completely capture the physics of the interaction of the laser beam with the water surface, column, and bottom. Many previous fitting approaches have been applied to represent lidar bathymetric waveforms. For example, two Gaussian functions were used to represent the surface and bottom returns. Because the column contribution shows an asymmetric shape physically corresponding to an infinite sum of successive translated Gaussian functions with an exponentially decreasing amplitude along time, i.e., water depth, it was previously approximated as a mixture of Gaussians in [10]. In Abdallah et al. [2], a Gaussian function, a triangular function, and a Weibull function were used to fit the surface contribution, the column contribution, and the bottom contribution, respectively. However, even with more suitable functions to fit each contribution, a bias in bathymetry estimates was also observed [2].

In this letter, we aim to define a new waveform fitting algorithm to retrieve bathymetry where 1) a quadrilateral function is used to better fit the water column contribution in addition to two Gaussian functions used to fit the surface and bottom contributions, and 2) it takes advantage of a nonlinear recursive optimization algorithm [11]. The benefit of the new fitting approach we propose is assessed on sets of both satellite and airborne simulated lidar waveforms. The results of bathymetry estimates (biases and standard deviations) computed using a quadrilateral function were compared with those obtained from a simple peak detection approach and using the triangle function fitting method initially proposed by Abdallah et al. [2]. 
TABLE I

Probabilities Distributions of Water PARAMETERS on CoAstal Waters [2]

\begin{tabular}{|c|c|c|}
\hline PARAMETERS & RANGES & DISTRIBUTION \\
\hline $\begin{array}{l}\text { WATER SURFACE } \\
\text { RUGOSITY R [14] }\end{array}$ & $0.1-0.5$ & UNIFORM \\
\hline BOTTOM ALBEDO $R_{B}$ & $0.05-0.2$ & UNIFORM \\
\hline $\begin{array}{c}\text { SPECULAR RATIO KS } \\
{[15]}\end{array}$ & $0.6-0.9$ & UNIFORM \\
\hline BOTTOM SLOPE SB $\left(^{\circ}\right)$ & $0-30$ & LOG-NORMAL $\left(\mu=3^{\circ}, \sigma=6^{\circ}\right)$ \\
\hline SURFACE SLOPE SS $\left({ }^{\circ}\right)$ & $0-1$ & UNIFORM \\
\hline $\begin{array}{c}\text { YELLOW SUBSTANCE } \\
\text { Ay0 }\left(\mathrm{m}^{-1}\right) \\
\end{array}$ & $0.06-3.82$ & $\begin{array}{c}\text { LOG-NORMAL } \\
(\mu=3.12, \sigma=1.24)\end{array}$ \\
\hline $\begin{array}{c}\text { PHYTOPLANKTON Ph } \\
\left(\mathrm{mg} / \mathrm{m}^{3}\right)\end{array}$ & $1-50$ & $\begin{array}{c}\text { LOG-NORMAL } \\
(\mu=-1.89, \sigma=1.58)\end{array}$ \\
\hline SEDIMENT S (mg/l) & $2.6-200$ & LOG-NORMAL $(\mu=2.97, \sigma=0.89)$ \\
\hline
\end{tabular}

Despite being basic and not robust compared with the operational methods of bathymetric lidar systems that use the correction calibration process to address biases in bathymetry (see [12] and [13]), a water depth estimate from a peak detection method was used here as the reference method to highlight the benefit of any waveform fitting method. Section II introduces the data sets, whereas Section III offers a brief presentation on the methodology used and the results obtained. In the last section, a summary of the results is given, and a discussion on bias sources is proposed.

\section{DATA SETS DESCRIPTION}

Three waveforms data sets were generated in using the recently developed Wa-LID code [1]. For each of the three data sets, the waveforms are the summation of the laser pulse convolution with the impulse response functions of the surface, column, and bottom, as well as additional noises.

The simulator governs both the water properties and the used sensor's specifications. The simulator also models solar radiation and detector noise [1]. Moreover, it includes the effects of pulse stretching, where the bottom return is stretched due to bottom slopes and incidence angle, reducing its amplitude. However, the Wa-LID simulator assumes that the water column is homogeneous, with the same optical properties for the whole column.

Waveforms were generated in using probability distributions for each water parameters. These distributions came from databases collected on coastal waters around the world and from published references [2]. They are assumed to be representative of what we can encountered at the global scale. The probability distributions of water properties that were used to generate the databases of simulated waveforms are presented in Table I.

We used parameters that correspond to two sensors, namely, satellite and airborne (see Table II). The parameters used for satellite data set modeling were chosen by the European Aeronautic Defence and Space (EADS)-Astrium Company [2] as a possible future satellite lidar bathymetry system. Airborne data set parameters were modeled using HawkEye sensor parameters [15]. In our simulations, we used the usual green wavelength $(532 \mathrm{~nm})$ common to many ALBs [16] because of the necessity for a tradeoff between the attenuation of the bottom return due to water absorption and the scattering and absorption by particles in the water. The field-of-view (FOV) angle for the HawkEye system ranges between 10 and 50 mrad.
TABLE II

Sensor Parameter Specifi cations [2], [4], [12]

\begin{tabular}{|c|c|c|}
\hline PARAMETERS & AIRBORNE & SATELLITE \\
\hline WAVELENGTH $\lambda(\mathrm{nm})$ & 532 & 532 \\
\hline ALTITUDE H $(\mathrm{km})$ & 0.2 & 500 \\
\hline LASER ENERGY E0 $(\mathrm{J})$ & $\underline{3.10^{-3}}$ & $\underline{5.10^{-3}}$ \\
\hline PULSE DURATION T 0 (ns) & 7 & 3.5 \\
\hline INCIDENCE ANGLE $\theta\left({ }^{\circ}\right)$ & $\underline{0}$ & 0 \\
\hline RECEIVER AREA AR $\left(\mathrm{m}^{2}\right)$ & $0 . \overline{025}$ & 0.63 \\
\hline FIELD OF VIEW FOV (rad) & $15.10^{-3}$ & $\underline{9.10^{-5}}$ \\
\hline RESPONSIVITY R $\lambda(\mathrm{A} / \mathrm{W})$ & 0.3 & 0.25 \\
\hline DIVERGENCE ANGLE (rad) & $15.10^{-3}$ & $6.10^{-5}$ \\
\hline EMITTED OPTICAL EFFICIENCY HE & 0.9 & 0.8 \\
\hline RECEIVER OPTICAL EFFICIENCY HR & 0.5 & 0.5 \\
\hline LOSS FACTOR F & 1 & 1 \\
\hline FILTER's BANDWIDTH $\Delta \lambda(\mathrm{nm})$ & 1 & 1 \\
\hline RECIEVER OBTURATION $\gamma R$ & 0.35 & 0.1 \\
\hline ELECTRICAL BANDWIDTH B (MHZ) & 142 & 500 \\
\hline EXCESS NOISE G & 3 & 3 \\
\hline DARK CURRENT ID (A) & $10^{-8}$ & $10^{-10}$ \\
\hline
\end{tabular}

The lower the FOV is, the lower is the solar radiation noise. For a very small FOV, however, the bottom contribution's power magnitude will be reduced, resulting in a lower maximum detectable depth. Thus, an FOV of $15 \mathrm{mrad}$ was chosen for the airborne simulation. For the sake of simplicity, we used an onnadir rather than an off-nadir angle.

In order to compute accuracy statistics on the bathymetry estimates (biases and standard deviations), the first data set was generated. Data set 1 contains 32000 simulated waveforms, 16000 waveforms for each sensor (airborne and satellite). For each sensor, the 16000 simulated waveforms come from 2000 waveforms for each one of the eight investigated water depths: $1,2,3,4,5,6,7$, and $10 \mathrm{~m}$. At a given water depth, the 2000 waveforms were generated with random water properties, according to the distributions in Table I.

In order to better investigate if the standard deviation in the bathymetry estimates comes from water column properties variations, from noise, or from the fitting process, a second data set was generated. Data set 2 contains 16000 simulated waveforms, 8000 waveforms for each one of the two sensors. For each sensor, the 8000 simulated waveforms come from 1000 waveforms for each one of the eight investigated water depths. At a given water depth, the 1000 generated waveforms differ from data set 1 by fixing the water column parameters to slightly turbid water (Yellow substance Ay0 $=0.07 \mathrm{~m}^{-1}$, Phytoplankton $\mathrm{Ph}=1 \mathrm{mg} / \mathrm{m}^{3}$, and Sediment $\mathrm{S}=2.6 \mathrm{mg} / \mathrm{l}$ ) [20]. The choice of slightly turbid water is to ensure better bottom peak detection at greater water depths. Computing the ratio between the obtained standard deviations of bathymetry estimates with variable (data set 1) or fixed water column properties (data set 2) allows measuring the sensitivity of standard deviation estimates to the variability of water column properties.

Finally, in order to verify that the bias of bathymetry estimates mainly comes from the water column return overlapping the surface and bottom water returns, a smaller third data set was generated. Data set 3 contains only 4000 simulated waveforms. Two thousand waveforms were generated for each sensor using a water depth of $3 \mathrm{~m}$. Indeed, these 4000 waveforms are a subset of the one simulated in data set 1 without the 
column contribution. This data set assumes a totally transparent water column. Next, these waveforms were processed with a bi-Gaussian fitting process (fitting both surface and bottom returns) in order to verify that the bathymetry bias disappears when the water column contribution is removed. For all simulated waveforms (data sets 1, 2, and 3), the effects of detector noise and noise due to solar radiation were integrated.

\section{Methodology}

\section{A. Peaks Detection Procedure}

To perform a water depth estimate, the lidar waveform should exhibit two distinct detectable peaks, representing the surface and bottom echoes. To facilitate the identification of the two peaks, denoising of lidar signal was applied using wavelet decomposition based on Stein's heuristic [19]. This step is essential in order to limit the effect of the solar radiation, particularly on the airborne waveforms. Next, a peaks detection procedure was used on the smoothed waveforms. It considers that a peak is any local maxima in the lidar waveform that has an amplitude much higher than the noise level (10 times for example). After identification of all peaks in the waveform, the peak with the smallest time bin is attributed to the surface position, and the peak with the largest time bin is attributed to the bottom position. Other peaks between the surface and bottom positions are commonly attributed to turbidity, marine life, or suspended particles in the water column [17].

\section{B. Waveform Fitting Procedure}

Next, a fitting procedure is applied to the waveforms. In this letter, we experimented with two fitting schemes that are both dependent on a nonlinear recursive least squares fitting algorithm [18], and we considered the surface and bottom returns to be Gaussian functions. However, the difference lies in the presentation of the water column: In one scheme, it is fitted into a triangular function [see Fig. 1(a)]; in the newly proposed scheme, it is fitted into a quadrilateral function [see Fig. 1(b)]. Fig. 1(c) shows that both fittings are superimposed on the simulated waveform without noise, which demonstrates efficient fitting in this schematic case. However, the quadrilateral function shows a better fitting to the shape of the water column contribution than the triangular function.

To evaluate the performance of those two fitting algorithms, the bias, i.e., the mean difference between the estimated and simulated water depths, and the standard deviation of the

bathymetry estimates were computed for each data set (satellite and airborne configurations).

For the proposed fitting method using a quadrilateral function

to fit the water column contribution, the fitted lidar waveform can be expressed as

$$
R(t)=f_{1}(t)+f_{2}(t)+f_{3}(t) .
$$

The fitted surface return $f_{1}(t)$ is given by

$$
f_{1}(t)=\frac{a_{1}}{\sigma_{1} \sqrt{2 \pi}} e^{-\frac{\left(t-\mu_{1}\right)^{2}}{2 \sigma_{1}^{2}}}
$$

where $a_{1}, \mu_{1}$, and $\sigma_{1}$ are the amplitude, the mean, and the standard deviation of the Gaussian function, respectively. (a)

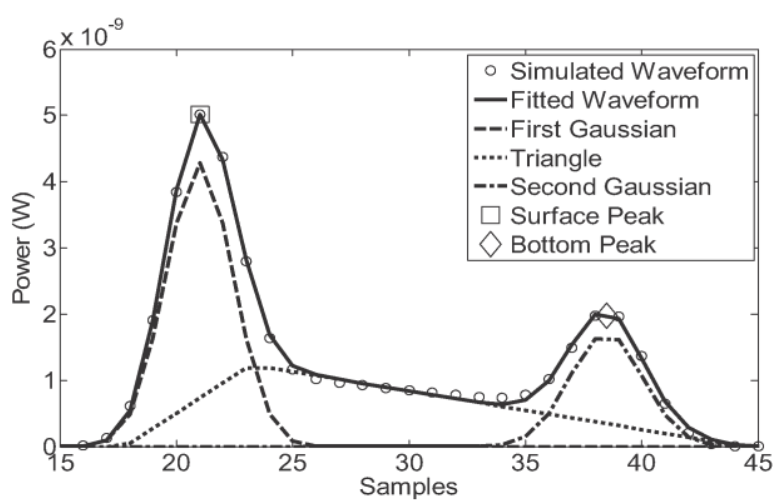

(b)

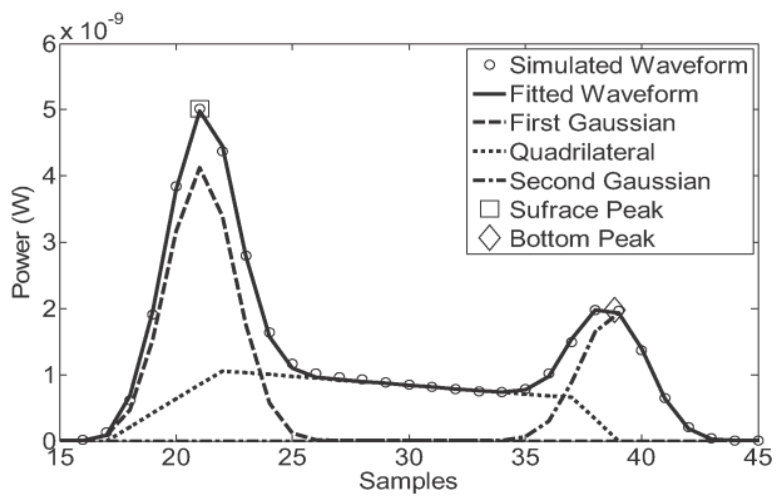

(c)

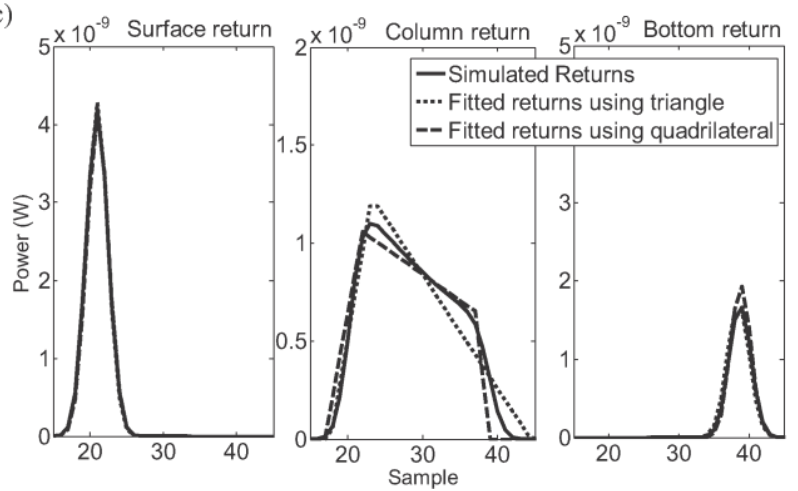

Fig. 1. (a) Triangular and (b) quadrilateral fitting of the column contribution for a simulated waveform without noise using satellite sensor parameters at a semipure water depth of $2 \mathrm{~m}(2 \mathrm{~m}=(38-21) \times 0.225 \times 0.5)$ sampled at 1 ns. (c) Quadrilateral and triangular fittings superimposed on the simulated contributions.

The fitted column return $f_{2}(t)$ is given by

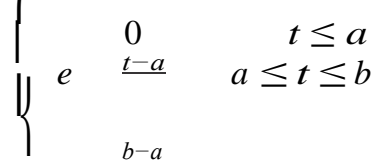

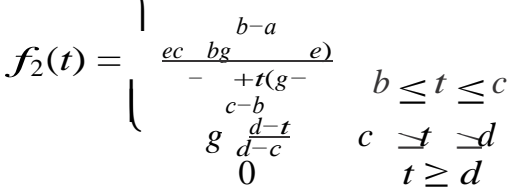

where $a, b, c$, and $d$ are the $x$-axis points for the quadrilateral; and $e$ and $g$ are the ordinates for the third and fourth points, respectively.

The fitted bottom return $f_{3}(t)$ is given by

$$
f_{3}(t)=\frac{a_{2}}{\sigma_{2}} e^{-\frac{\left(t-\mu_{2}\right)^{2}}{2 \pi}}
$$




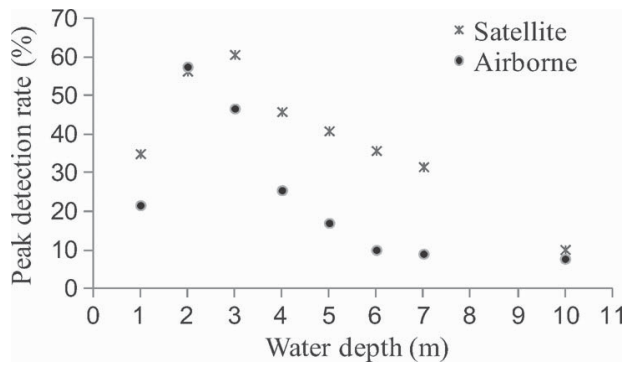

Fig. 2. Peak detection rate (in percentage) versus water depth (in meters).

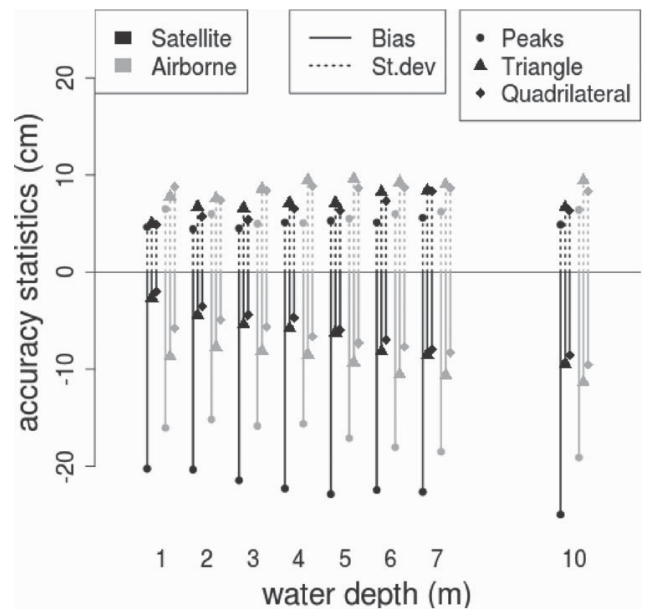

Fig. 3. Bias and standard deviation on bathymetry estimates (in centimeters) versus water depth (in meters) (computed on data set 1).

where $a_{2}, \mu_{2}$, and $\sigma_{2}$ are the amplitude, the mean and the standard deviation of the Gaussian function, respectively.

\section{RESULTS}

\section{A. Satellite Sensor}

Of the overall satellite waveforms, $39.6 \%$ were detectable, i.e., having identified peaks. Fig. 2 shows the detection rate at each depth. As expected, the detection probability increases until it reaches a water depth of $3 \mathrm{~m}$ as a result of the dependence of the detection rate on the merger of the surface return with the bottom's return at shallow depths. At water depths greater than $3 \mathrm{~m}$, the peak detection rate decreases as the water depth increases due to attenuation and absorption.

After applying peak detection, the fitting procedure was applied to the waveforms that had a detectable bottom. Fig. 3 shows that the bias insignificantly increases as the water depth increases, where it increased from $-20.3 \mathrm{~cm}$ at a water depth of $1 \mathrm{~m}$ to $-25.0 \mathrm{~cm}$ at a depth of $10 \mathrm{~m}$ using the peak detection method. When using quadrilateral fitting, the bias increased from $-2.0 \mathrm{~cm}$ at a water depth of $1 \mathrm{~m}$ to $-8.5 \mathrm{~cm}$ at a depth of $10 \mathrm{~m}$. For the triangular fitting, the bias increased from $-2.7 \mathrm{~cm}$ at a water depth of $1 \mathrm{~m}$ to $-9.4 \mathrm{~cm}$ at a depth of $10 \mathrm{~m}$. This increase in bias is most likely due to the weaker bottom return at greater water depths. Fig. 3 also displays the standard deviation. Upon examination, we notice that, for the quadrilateral fitting, the standard deviation is slightly lower than that for the triangular fitting. Using the quadrilateral function, the standard deviation ranges between 4.8 and $8.3 \mathrm{~cm}$.
TABLE III

Overall Bathymetry Accuracy (Biases and Standard Deviations in Centimeters) Using All Investigated Water Depths ) (Computed on Data Set 1)

\begin{tabular}{cccc}
\hline & PEAK & FitTING USING & FitTING USING \\
DETECTION & TRIANGLE & QUADRILATERAL \\
SATELLITE & $-21.8 \pm 4.9$ & $-5.8 \pm 7.0$ & $-5.0 \pm 6.0$ \\
BIAS \pm STD & & & $-6.1 \pm 8.2$ \\
AIRBORNE & $-16.1 \pm 5.7$ & $-8.5 \pm 8.5$ & \\
BIAS \pm STD & &
\end{tabular}

However, using the triangular function, the standard deviation ranges between 5.0 and $8.4 \mathrm{~cm}$. The overall bias and standard deviation for all the used water depths are shown in Table III, which clearly portrays the improvement in reducing the bias by $16 \mathrm{~cm}$ in magnitude when using the fitting procedure based on the quadrilateral function.

Next, to scrutinize how far the overall $6-\mathrm{cm}$ standard deviation obtained on data set 1 (see Table III) is caused by the waveform variability due to the water column properties variability, the standard deviation of the bathymetry estimates after applying the quadrilateral function algorithm on data set 2 was computed. The obtained overall standard deviation of bathymetry estimates is thus $1.3 \mathrm{~cm}$. When comparing this $1.3 \mathrm{~cm}$ to the $6 \mathrm{~cm}$ obtained on data set 1 , we can deduce that $78 \%$ (equal to $1-1.3 / 6$ ) of the $6-\mathrm{cm}$ standard deviation is a result of the variability of water column parameters, whereas the remaining part (22\%) can be due to the variability in the fitting due to random noise. Of course, this result is dependent to the studied sensor characteristics and the water column parameters distribution we chose.

In order to verify that the bias of bathymetry estimates mainly comes from the water column return overlapping the surface and bottom returns, we computed the bias using a biGaussian function fitting of the 4000 waveforms from the third data set (one Gaussian for each of the surface and bottom peaks). Next, we compared this bias to the one computed using the 4000 waveforms at a water depth of $3 \mathrm{~m}$ from the first data set (waveforms with surface, bottom, and column contributions). The obtained bias was near zero for data set 3 and was approximately $-4.5 \mathrm{~cm}$ for data set 1 . This result leads us to consider that the bias is inherent to the summation of the three contributions (surface, column, and bottom) that are overlapping. These overlaps cause a translation in time of the peaks, which do not correspond to central surface and bottom positions. To reduce this bias, a statistical approach introducing a calibrated offset parameter could be designed to better fit the data during actual surveys.

\section{B. Airborne Sensor}

For the airborne data set, the overall detection rate was $24.4 \%$. The peak detection rate (see Fig. 2) has a similar distribution to that from the satellite data set, except that the detection rate starts decreasing at a water depth of $2 \mathrm{~m}$, which can be explained by the differences in airborne and satellite sensor parameters (e.g., $T_{0}$ and $H$ ). Indeed, the overlap between column and bottom contributions increases when the emitted pulse $\left(T_{0}\right)$ increases. Moreover, the sensor altitude $(H)$ affects the results by acting on contribution (surface, column, and bottom) magnitude due to air column transmittance. 
The bias at each water depth for the airborne data set (see Fig. 3) also slightly increases as the water depth increases, ranging from -5.7 to $-9.6 \mathrm{~cm}$ for the quadrilateral fitting, which is better than -8.7 to $-11.5 \mathrm{~cm}$ obtained for the triangular fitting. Additionally, it shows an obvious improvement compared with using only the peak detection method, which increased from $-16.0 \mathrm{~cm}$ at a water depth of $1 \mathrm{~m}$ to $-19.1 \mathrm{~cm}$ at a water depth of $10 \mathrm{~m}$. Once again, the performance of the quadrilateral fitting is slightly better than the triangular fitting. Fig. 3 also displays the standard deviation, which is nearly identical over all water depths, ranging from 7.3 to $8.7 \mathrm{~cm}$ when using the quadrilateral fitting and 7.8 to $9.4 \mathrm{~cm}$ when using the triangular fitting. The increase in the standard deviation compared with the satellite data set is due to higher solar radiation noise in the airborne data set. The overall bias (see Table III) shows an improvement of approximately $10 \mathrm{~cm}$ in the bias when using the quadrilateral fitting procedure compared with simple peak detection. In order to also assess how far the $8.2-\mathrm{cm}$ (see Table III) overall standard deviation in bathymetry estimates from the airborne data set is caused by the water column properties variability, a similar computation to that performed for the satellite data set was computed. The computed standard deviation of the bathymetry estimates after applying the quadrilateral function algorithm on data set 2 is $5.1 \mathrm{~cm}$. Compared with the $8.2 \mathrm{~cm}$ obtained on data set 1 (see Table III), we can deduce that only $38 \%$ of the $8.2-\mathrm{cm}$ standard deviation is a result of the variability of water column parameters.

To ensure that the bias is also coming from the column contribution overlapping the surface and bottom returns, as in the satellite data set, we used the simulated airborne data set 3 at a water depth of $3 \mathrm{~m}$. Once again, the bias computed on data set 3 was negligible. This result proves that, for this data set as well, the source of the bias was due to the overlap of the column contribution on the surface and bottom returns.

\section{CONCLUSION}

In this letter, a new lidar fitting algorithm to retrieve bathymetry has been tested on simulated waveform data sets. Two lidar sensor configurations were used to simulate these waveforms, one using satellite sensor parameters and the other using airborne sensor parameters. The bathymetry detection rate was established depending on the number of waveforms that incorporate more than one peak. The estimation accuracy was evaluated based on the bias and standard deviation for each data set (satellite and airborne). It is highlighted that the bias depended on the column contribution being added to the surface and column returns, which caused a shift in the surface and bottom peaks that led to a bias in the water depth estimate. However, the fitting algorithm we proposed showed a clear improvement compared with the water depth estimate coming from simple peak detection, and it showed a slight improvement over fitting alternatives using a triangular function. For the simulated satellite data set using the quadrilateral function, the results showed an improvement of $16.8 \mathrm{~cm}$ in the bias compared with the basic peak detection method. For the simulated noisier airborne data set, the improvement in bias was lower, at approximately $10.0 \mathrm{~cm}$. Subsequently, the quadrilateral function produced slightly more unbiased estimations than the triangular function in both data sets. Moreover, the fitting using a quadri- lateral function showed a slightly better standard deviation, with $6.0 \mathrm{~cm}$ for the satellite data set and $8.2 \mathrm{~cm}$ for the airborne, compared with the fitting using a triangular function, with $7.0 \mathrm{~cm}$ for the satellite data set and $8.5 \mathrm{~cm}$ for the airborne data set.

\section{ACKNOWLEDGMENT}

The authors would like to thank F. Fabre from the EADS Company for his useful advice.

\section{REFERENCES}

[1] H. Abdallah, N. Baghdadi, J. S. Bailly, Y. Pastol, and F. Fabre, "Wa-LiD: A new LiDAR simulator for waters," IEEE Geosci. Remote Sens. Lett., vol. 9, no. 4, pp. 744-749, Jul. 2012.

[2] H. Abdallah, J. S. Bailly, N. Baghdadi, N. Saint-Geours, and F. Fabre, "Potential of space-borne LiDAR sensors for global bathymetry in coastal and inland waters," IEEE J. Sel. Topics Appl. Earth Obser. Remote Sens., vol. 6, no. 1, pp. 202-216, Feb. 2013.

[3] H. M. Tulldahl and K. O. Steinvall, "Simulation of sea surface wave influence on small target detection with airborne laser depth sounding," Opt. Soc. Amer, vol. 43, no. 12, pp. 2462-2483, Apr. 2004.

[4] H. M. Tulldahl and K. O. Steinvall, "Analytical waveform generation from small objects in LiDAR bathymetry," Appl. Opt., vol. 38, no. 6 , pp. 1021-1039, 1999.

[5] N. Battaglia, "Utility of satellite LIDAR waveform data in shallow water," M.S. thesis, Appl. Phys. Div., Naval Postgraduate School, Monterey, CA, USA, Jun. 2010.

[6] A. Mohammadzadeh and M. J. Valdan Zoej, "A state of art on airborne lidar application in hydrology and oceanography: A comprehensive overview," presented at the International Archives Photogrammetry, Remote Sensing, Spatial Information Sciences, Beijing, China, 2008, Part B1.

[7] J. L. Irish, An Introduction to Coastal Zone Mapping With Airborne LIDAR: The SHOALS System. Mobile, AL, USA: Joint Aireborne Lidar Bathymetry Tech. Center Expertise, Coastal Hydrolic Lab., US Army Eng. Res. Dev. Center, 2000.

[8] C. K. Wang and W. D. Philpot, "Using airborne bathymetric lidar to detect bottom type variation in shallow waters," Remote Sens. Environ., vol. 106, no. 1, pp. 123-135, Jan. 2007.

[9] T. Allouis, J. S. Bailly, Y. Pastol, and C. Le Roux, "Comparison of LiDAR waveform processing methods for very shallow water bathymetry using Raman, near-infrared and green signals," Earth Surface Process. Landforms, vol. 35, no. 6, pp. 740-750, May 2010.

[10] B. Long, A. Cottin, and A. Collin, "What Optech's bathymetric LiDAR sees underwater," Geosci Remote Sens. Symp., pp. 3170-3173, 2007.

[11] I. Griva, S. G. Nash, and A. Sofer, "Nonlinear optimization," in Linear Nonlinear Optimization, 2nd ed. Philadelphia, PA, USA: SIAM, 2009, ch. 14 , pp. 483-549.

[12] G. C. Guenther, "Airborne Laser Hydrology System Design and Performance Factors," National Oceanic Atmospheric Administration, Rockville, MD, USA, 1985, Library of Congress 85-600602.

[13] G. C. Guenther, A. G. Cunningham, P. E. LaRocque, and D. J. Reid, "Meeting the accuracy challenge in airborne LiDAR bathymetry," in Proc. 20th EARSeL Symp., Workshop LiDAR Remote Sens. Land Sea, Dresden, Germany, Jun. 16-17, 2000, pp. 1-27.

[14] R. L. Cook and K. E. Torrance, "A reflectance model for computer graphics," ACM Trans. Graph., vol. 1, no. 1, pp. 7-24, Jan. 1982.

[15] P. Beckmann and A. Spizzochino, The Scatter of Electromagnetic Waves From Rough Surfaces. Norwood, MA, USA: Artech House, 1987.

[16] A. Axelsson, "Rapid topographic and bathymetric reconnaissance using airborne LiDAR," in Proc. Soc. Photo-Opt. Instrum. Eng., 2010, vol. 7835.

[17] P. J. Kinzel, C. W. Wright, J. M. Nelson, and A. R. Burman, "Evaluation of an experimental LiDAR for surveying a shallow, braided, sandbedded river," US Geological Survey, vol. 133, no. 7, pp. 838-842, Jul. 2007.

[18] D. W. Marquardt, "An algorithm for least-squares estimation of nonlinear parameters," J. Soc. Ind. Appl. Math., vol. 11, no. 2, pp. 431-441, 1963.

[19] C. Qiang and Z. Guo, "A noise reduction approach based on Stein's unbiased risk estimate," Sci. Asia, vol. 38, no. 2, pp. 207-211, 2012.

[20] R. C. Smith and K. S. Baker, "Optical properties of the clearest natural waters (200-800 nm)," Appl. Opt., vol. 20, no. 2, pp. 177-184, 1981. 